\title{
MANAGEMENT OF ENDOCRINE DISEASE Metabolic effects of bariatric surgery
}

\author{
Ricard Corcelles $^{1,2}$, Christopher R Daigle ${ }^{1}$ and Philip R Schauer ${ }^{1}$ \\ ${ }^{1}$ Bariatric and Metabolic Institute, Cleveland Clinic, 9500 Euclid Avenue, M61 Cleveland, OH 44195, USA and \\ ${ }^{2}$ Department of Gastrointestinal Surgery, Institute of Digestive and Metabolic Diseases, Fundació Clínic per a la \\ Recerca Biomèdica, Hospital Clinic de Barcelona, Barcelona, Spain
}

Correspondence

should be addressed

to P R Schauer

Email

schauep@ccf.org

\begin{abstract}
Obesity is associated with an increased risk of type 2 diabetes, hypertension, dyslipidemia, cardiovascular disease, osteoarthritis, numerous cancers and increased mortality. It is estimated that at least 2.8 million adults die each year due to obesity-related cardiovascular disease. Increasing in parallel with the global obesity problem is metabolic syndrome, which has also reached epidemic levels. Numerous studies have demonstrated that bariatric surgery is associated with significant and durable weight loss with associated improvement of obesity-related comorbidities. This review aims to summarize the effects of bariatric surgery on the components of metabolic syndrome (hyperglycemia, hyperlipidemia and hypertension), weight loss, perioperative morbidity and mortality, and the long-term impact on cardiovascular risk and mortality.
\end{abstract}

\section{Introduction}

Obesity is an epidemic on the rise. The World Health Organization projects that by $2015, \sim 2.3$ billion adults will be overweight and more than 700 million will be obese (1). Obesity is associated with an increased risk of type 2 diabetes (T2DM), hypertension, dyslipidemia, cardiovascular disease, osteoarthritis, numerous cancers and increased mortality (2). It is estimated that at least 2.8 million adults die each year due to obesity-related cardiovascular disease (3). Increasing in parallel with the global obesity problem is metabolic syndrome, which has also reached epidemic levels. The National Health and Nutrition Examination Survey reported that 34\% of American adults have metabolic syndrome based on the National Cholesterol Education Program Adult Treatment Panel III criteria: waist circumference $\geq 102 \mathrm{~cm}$ (men) or $\geq 88 \mathrm{~cm}$ (women), triglycerides $\geq 150 \mathrm{mg} / \mathrm{dl}$, HDL $<40 \mathrm{mg} / \mathrm{dl}$ (men) or $<50 \mathrm{mg} / \mathrm{dl}$ (women), hypertension $\geq 130 / 85 \mathrm{mmHg}$ and fasting glucose $\geq 100 \mathrm{mg} / \mathrm{dl}$ (4). Conventional treatments such as diet, lifestyle modification, exercise and pharmacotherapy have failed to

Invited Authors' profiles

Ricard Corcelles is consultant surgeon, Division of Gastrointestinal Surgery, Hospital Clínic Barcelona, University of Barcelona, Spain. He specializes in the field of minimally invasive surgery and has dedicated part of his career to the realm of metabolic and bariatric surgery.

Philip R Schauer is Chief of Minimally Invasive General Surgery and Director of the Cleveland Clinic Bariatric and Metabolic Institute. He is also Professor of Surgery at the Cleveland Clinic Lerner College of Medicine of Case Western Reserve University. In addition, he is a former president of the American Society for Metabolic and Bariatric Surgery.

(C) 2016 European Society of Endocrinology Printed in Great Britain
Published by Bioscientifica Ltd. 
achieve satisfactory sustained weight loss. In addition, the direct cost of obesity in the United States is extremely high, with an estimated $\$ 190$ billion spent in 2010 (5).

Numerous studies have demonstrated that bariatric surgery is associated with significant and durable weight loss and associated improvement of obesity-related comorbidities $(6,7,8)$. Furthermore, the beneficial effects of bariatric surgery on mortality, overall disease-specific risk reduction and long-term quality of life are well documented $(9,10,11,12)$. The degree of the effect on obesity-related comorbid conditions depends on the bariatric surgical approach, typically classified based on its restrictive and/or malabsorptive effect. Current data from the International Federation for the Surgery of Obesity and Metabolic Diseases (IFSO) reports that the most commonly performed procedures are the Roux-en-Y gastric bypass (RYGB) (45\%), sleeve gastrectomy (SG) (37\%), adjustable gastric banding (AGB) (10\%) and biliopancreatic diversion (BPD) with or without duodenal switch (DS) (2.5\%) (13). This review aims to summarize the effects of bariatric surgery on the components of metabolic syndrome (hyperglycemia, hyperlipidemia and hypertension), weight loss, perioperative morbidity and mortality, and the long-term impact on cardiovascular risk and mortality.

\section{Weight loss}

Historically, the primary endpoint of bariatric surgical procedures has been weight loss and the reported weight loss achieved is generally sustained $(14,15)$. The overall percentage of excess weight loss (EWL) has been reported to be $47-70 \%$ in long-term series (16). Unfortunately, there is a relative lack of randomized controlled trials with long-term results addressing this primary endpoint. In the controlled Swedish Obesity Study (SOS), patients were prospectively followed over 20 years and those who underwent bariatric surgery retained $18 \%$ of weight loss compared to $1 \%$ in the non-surgical group. The mean 20 -year weight reduction was $15 \%$ for AGB and $25 \%$ for RYGB patients (14). A systematic review conducted by O'Brien et al. (17) detected sustained EWL $>50 \%$ for AGB and RYGB at 8 and 10 years respectively.

Malabsorptive procedures such as BPD and RYGB achieve a greater percentage of EWL and more durable weight loss when compared to purely restrictive operations. However, this benefit comes at a cost of higher complications rates. Specifically, BPD provides the greatest weight loss in most published series but also has higher complication rates than less aggressive bariatric approaches. A retrospective review of the Bariatric Outcomes Longitudinal Database (BOLD) from 2007 to 2010 showed 79\% EWL for BPD-DS compared with $67 \%$ EWL for RYGB at 2 years follow-up (18).

While O'Brien et al. (19) have recently reported $47 \%$ EWL in a cohort of 3227 patients followed over a 15-year span, AGB is still considered a purely restrictive procedure with the lowest durable weight loss. For instance, a recent meta-analysis by Chakravarty et al. (20) including five randomized controlled trials comparing AGB with other procedures concluded that AGB is associated with less weight loss. Since its introduction in 2007, SG case volumes have increased dramatically, with published weight loss results comparable to RYGB. SG is considered a restrictive procedure; however, it has been increasingly recognized to have metabolic effects similar to those observed after RYGB (21). A recent 5-year outcomes study has reported successful SG results, with an $86 \%$ average EWL (22). However, other studies have demonstrated more modest long-term weight loss results (especially in patients with BMI $>50 \mathrm{~kg} / \mathrm{m}^{2}$ ), with many patients ultimately requiring revision surgery for inadequate weight loss or recidivism (23).

\section{Complications of metabolic surgery}

In their systematic review and meta-analysis (the most cited paper in bariatric surgery), Buchwald et al. (24) reported exceptionally low early and late mortality rates after bariatric operations ( 0.28 and $0.35 \%$ respectively). Mortality was higher in open and conversion cases $(0.30$ and $0.07 \%$ respectively), the male gender (male:female ratio of 4.7:01) and super obese subjects (range, $0.8-1.2 \%$ ). Open cases were considered those undergoing bariatric surgery via laparotomy, while conversions were defined as conversion from a laparoscopic procedure to an open (conventional) surgery (24). Similarly, a prospective, multicenter, observational study of 30-day outcomes in 4776 consecutive patients undergoing bariatric surgical procedures reported a comparably low perioperative mortality rate of $0.3 \%$ (8).

After bariatric surgery, cardiopulmonary complications such as myocardial infarction and pulmonary embolism are the major causes of mortality, representing $70 \%$ of all deaths (25). The overall mortality rate for RYGB performed in centers of excellence is $0.4 \%$ (8). The most serious procedure-specific early complication after RYGB is anastomotic leakage, with an incidence ranging from 0.1 to $5.6 \%$. Patients at higher risk are those with higher BMI, older age, males, with multiple comorbidities, smoking, 
or prior revision operations. AGB is a safe procedure with $0.3 \%$ or less mortality rate (26). However, late complications such as band slippage, erosion, migration, port infection and gastroesophageal perforations are well documented and occur in about $20 \%$ of patients (27). In addition, long-term weight loss failure rates of over $50 \%$ have been reported, and this has led to a significant increase in revisions of AGB to RYGB or SG (28).

Procedure-specific late complications presenting clinically as bowel obstruction after RYGB include internal hernias and gastrojejunal anastomotic stricture. Internal hernias are more common after laparoscopic cases and range from 0.5 to $9.0 \%$ (29). Abdominal pain with or without clinical signs of bowel obstruction is the most common presentation, and diagnostic laparoscopy is the method of choice due to high false negative rates associated with abdominal computerized tomography (CT) scans (30). The incidence of gastrojejunal anastomotic stricture is about $10 \%$ and possible mechanisms include ischemia, excessive scarring, recurrent marginal ulcer and technical considerations such as excessive tension or torsion of the anastomosis. Endoscopy is the preferred tool for both diagnosis and treatment of gastrojejunal stricture (31). Gastrointestinal bleeding after RYGB is another uncommon late complication, typically caused by marginal ulceration. Marginal ulcers occur in $2 \%$ of patients within the first postoperative year, and then in $0.5 \%$ for up to 5 years (32). However, a recent study has shown significantly higher marginal ulceration rates (34\%) in 328 symptomatic patients who underwent endoscopic exploration after RYGB. Uni- and multi-variate analyses for associated risk factors identified tobacco as the most significant risk factor for marginal ulceration recurrence (33).

Major nutritional complications are typically associated with the malabsorptive effect of bariatric procedures and are usually seen after BPD, RYGB and, less commonly, AGB. Anemia is extremely common after RYGB and iron deficiency ranges from 17 to $50 \%$; the etiology is believed to be multifactorial in nature. Importantly, Love et al. (34) reported an iron deficiency incidence of up to $50 \%$ in premenopausal women. Deficiencies in other trace minerals (selenium, zinc and cooper) and vitamins (B12, B1, A, E, D and K) are commonly observed after bariatric procedures (35), specifically after BPD with or without DS (50-69\%). Severe calcium and vitamin D deficiencies have been described after BPD and very long limb RYGB, leading to decreased bone mineral density and osteoporosis. Protein malnutrition can also occur after these malabsorptive operations, and lifelong monitoring for nutritional complications is mandatory following these procedures (23).

\section{Metabolic outcomes of bariatric surgery}

\section{Effects on glycemic control}

Substantial evidence from observational data indicates that bariatric surgery is very effective in controlling T2DM, with high remission rates and reductions in anti-diabetic drug usage. Yet, not all bariatric procedures have demonstrated the same impact on glucose homeostasis. In the first large meta-analysis $(n=22094)$ published in 2004, Buchwald et al. found that bariatric surgery achieved complete diabetes resolution in $76.8 \%$ of subjects. The results differed dramatically by the type of surgery, ranging from $48 \%$ remission rates with AGB to $84 \%$ remission rates with RYGB and 99\% remission with biliopancreatic procedures (16). The authors concluded that malabsorptive procedures were the most effective with respect to T2DM control. Data from the BOLD, a national database for the American Society for Metabolic and Bariatric Surgery (ASMBS) Center of Excellence Program ( $n=23106$ patients), reported the highest 12-month diabetes remission rates for BPD-DS (74\%), followed by RYGB (62\%), SG (52\%) and AGB (28\%) (36).

Many observational studies have reported long-term diabetes remission rates $(14,37)$. A meta-analysis conducted by Buchwald et al. (38) including 621 studies with 135246 patients (all types of bariatric surgery) reported that $78 \%$ of diabetic patients had complete resolution (HbA1c $<6.5 \%$ and no anti-diabetic drugs) and $86.6 \%$ had diabetes improvement. Several factors have been reported to be predictors of T2DM remission, including shorter duration of diabetes, greater weight loss, previous treatment with lifestyle modification and former oral antidiabetic agent usage. Conversely, longer duration of diabetes, decreased weight loss, severity of diabetes and insulin requirements are factors associated with inadequate glycemic control after surgery $(23,39,40)$. In a study by Brethauer et al. (41) clinical outcomes of 217 patients with T2DM who underwent bariatric surgery between 2004 and 2007 and had at least 5-year follow-up were assessed (RYGB, $n=162 ; \mathrm{AGB}, n=32 ; \mathrm{SG}, n=23$ ). Complete remission was defined as $\mathrm{HbA1c}<6 \%$ and fasting blood glucose $<100 \mathrm{mg} / \mathrm{dl}$ off diabetic medications. The mean EWL was $55 \%$ and the mean HbA1c level decreased from $7.5 \pm 1.5 \%$ to $6.5 \pm 1.2 \%(P<0.001)$. Shorter duration of T2DM $(P<0.001)$ and higher longterm EWL $(P=0.006)$ predicted long-term remission. 
Recurrence of T2DM after initial remission occurred in $19 \%$ and was associated with longer duration of T2DM $(P=0.03)$, less EWL $(P=0.02)$, and weight regain $(P=0.015)$. Of note, the number of years after bariatric surgery is another predictive factor of relapse of diabetes that has been reported in the literature (40).

While many non-controlled studies have reported excellent improvements in glycemic control after bariatric surgery, direct comparisons with intense medical treatment are scarce. The results of the SOS study, a non-randomized trial comparing medical therapy with bariatric surgery, demonstrated higher rates of diabetes resolution at 2, 10 and 20 years follow-up in the bariatric surgery cohorts (14). The SOS study also reported significant benefits in the surgical arms with regards to long-term complications, major cardiovascular events and mortality of any cause. However, the SOS study investigators have recently reported a decline in T2DM remission rates at 15 years follow-up from 72.3 to $30.4 \%$ (42).

Five short-term (1-2 years follow-up) randomized controlled trials comparing bariatric surgery with medical treatment have been published $(42,43,44,45,46,47)$. The first randomized controlled trial by Dixon et al. in 2008 evaluated laparoscopic AGB vs pharmacotherapy and lifestyle intervention ( $n=60$, obese patients with T2DM). The surgical group achieved T2DM remission in 73\% compared to $13 \%$ in the nonsurgical group ( 2 years followup). Of note, weight loss was significantly higher in the surgical group (20.7\% vs $1.7 \%$ ) (42). Mingrone et al. randomly assigned 60 obese T2DM patients to receive conventional medical therapy or undergo either RYGB or BPD. Subjects included in the trial had diabetes for at least 5 years, BMI $\geq 35 \mathrm{~kg} / \mathrm{m}^{2}$, and $\mathrm{HbA} 1 \mathrm{c}$ of $7.0 \%$ or greater. The major endpoint was the rate of remission (defined as $\mathrm{HbA1c}$ level $<6.5 \%$ ). At 2 years, the remission rate was $0 \%$ for medical treatment, $75 \%$ for the RYGB group and 95\% in the BPD group ( $P<0.001$ for both comparisons) (44).

At the Cleveland Clinic, we randomized 150 patients with T2DM to conventional medical therapy, RYGB or SG. The primary endpoint of the 'Surgical Treatment and Medications Potentially Eradicate Diabetes Efficiently' (STAMPEDE) study was the proportion of patients achieving $\mathrm{HbA} 1 \mathrm{c}$ of $6.0 \%$ or less 12 months after treatment. A total of $42 \%$ in the RYGB arm, $37 \%$ in the SG arm and $12 \%$ in the medical group achieved remission at 1 year. The mean $\mathrm{HbA} 1 \mathrm{c}$ level was $7.5 \pm 1.8 \%$ in the medical therapy group, $6.6 \pm 1.0 \%$ in the SG group, and $6.4 \pm 0.9 \%$ in the RYGB group. Mean weight loss was $5.4 \mathrm{~kg}$ in the medically treated group vs 25.1 and $29.4 \mathrm{~kg}$ in the SG and RYGB groups, respectively. Complications were higher in the
RYGB cohort and least in the conventional medical therapy group (45). The Diabetes Surgery Study was a 12-month non-blinded randomized trial involving 120 participants (T2DM for at least 6 months, HbA1c level of $8.0 \%$ or higher and BMI $30-40 \mathrm{~kg} / \mathrm{m}^{2}$ ) at four teaching hospitals in the United States and Taiwan (43). In this study, intensive lifestyle modification and medical intervention was compared to RYGB. The primary endpoint (HbA1c level below 7\%) was reached by $48.5 \%$ of the RYGB cohort and $19 \%$ of the medical therapy group. However, patients in the surgical arm had 50\% more serious adverse events than the medical treatment-only group. Liang et al. compared three treatment arms in 108 obese T2DM patients with hypertension: conventional medical therapy, conventional medical therapy plus Exenatide (glucagon-like peptide-1 agonist) and surgical intervention (RYGB). At 12 months follow-up, diabetes remission had occurred in neither of the medical therapy groups vs $90 \%$ in the metabolic surgery arm. There was a significant decrease in antihypertensive drug requirements in the surgical group compared with medical groups $(P<0.05)(47)$.

We recently published the STAMPEDE 3-year outcomes (randomization of 150 patients with uncontrolled T2DM to intensive medical therapy alone or intensive medical therapy plus RYGB or SG) with $91 \%$ of patients completing follow-up. At 36 months, the primary endpoint (HbA1c level $\leq 6 \%$ ) was achieved by $5 \%$ of patients in the medical group compared with $38 \%$ in the RYGB arm and $24 \%$ in the SG arm $(P=0.01)(46)$. Furthermore, the use of anti-diabetic medications (including insulin) was lower in both surgical groups when compared to the medial therapy cohort. The surgically treated patients had improved glycemic control at 3 years and more than $90 \%$ of patients had glycemic control without the use of insulin. Weight loss and shorter duration of diabetes were the main predictors of $\mathrm{HbA1c}$ level $\leq 6 \%$ after surgery (46). The results of our study suggest that bariatric surgery is superior to intensive medical therapy alone in glycemic control after 3 years of randomization.

\section{Mechanisms underlying glycemic control}

There are many theories with regard to the mechanisms underlying the beneficial metabolic effects of bariatric surgery. Several studies have reported early resolution of T2DM 1 month after RYGB, with metabolic improvements greater than expected for the magnitude of weight lost (48). These data suggest a weight loss-independent effect of RYGB on glucose homeostasis control. Conversely, 
glycemic improvement following AGB appears to be related to the amount of weight loss. Thus, AGB appears to lack weight-independent effects on metabolic disease since remission of diabetes occurs gradually and in parallel with weight loss (42).

The mechanisms by which RYGB improves metabolic profiles have been thoroughly studied. In addition to the restriction related to the gastric pouch and the malabsorption associated with bypassing the proximal small bowel, there are two accepted theories on the benefits of RYGB on T2DM control (49). The 'foregut hypothesis' is based on the importance of duodenal exclusion and is supported by rat studies where the duodenal-jejunal bypass leads to glycemic improvement. Interestingly, this beneficial effect is not sustained when the gastro-jejunal nutrient transit is restored (50). Novel devices like the EndoBarrier Endoluminal Sleeve (GI Dynamics Inc., Lexington, MA, USA) try to mimic the anti-diabetic effect of RYGB by excluding the duodenum and proximal jejunum from nutrient transit (based on the 'foregut hypothesis') (51). In contrast, the 'hindgut hypothesis' is supported by the observation that rapid delivery of nutrients to the distal small bowel results in exaggerated gut hormone secretion, in particular GLP-1. This hypothesis is best illustrated in animal studies where rats undergo ileal interposition surgery (interposition of a segment of ileum to a segment of proximal small bowel) that has shown similar effects to those observed via RYGB (52).

GLP-1 has numerous metabolic effects but probably the most important is its ability to enhance B-cell function (53). The rapid entry and absorption of nutrients in the distal small bowel induces GLP-1 increases (up to threefold), which is secreted by L-cells from the gut and improves beta cell function and insulin sensitivity (54). The important role of GLP-1 has been demonstrated in studies using GLP-1 receptor antagonists that eliminate beneficial glycemic effects after RYGB (55). Postprandial levels of GLP-1 are observed to be enhanced after both SG and RYGB in human and rodent models, suggesting that alterations in intestinal hormone secretion are of significant importance with respect to the metabolic benefit of these procedures $(56,57,58)$. Changes in GLP-1 levels were studied in T2DM obese patients (T2DM for $<5$ years) before and 1 month after RYGB. Interestingly, oral glucose-stimulated GLP-1 (AUC) and gastric inhibitory peptide (GIP) peak levels increased significantly, compared to controls (59). Despite this, some authors have suggested that GLP-1 is likely not involved in diabetes improvement after bariatric surgery (60). Functional studies designed to assess the influence of GLP-1 signaling have obtained mixed results $(57,58,61)$.
The results of pharmacological blockade of the action of GLP-1 on its receptor (promoting prandial insulin release inhibition) tend to argue against GLP-1 being critical in diabetes remission after SG or RYGB. Several studies have shown modest impairment in glycemic control after GLP-1 receptor blockade, indicating that the contribution of endogenous GLP-1 after bariatric surgery to pancreatic beta cell function may only be minor (62).

The SG operation (no gastrointestinal rearrangements) has also been shown to have metabolic effects. Many studies have shown incretin upregulation after SG (63) and some reports suggest that RYGB and SG are associated with comparable remission rates of T2DM (64).

Numerous other factors have been implicated as potential contributors in the metabolic improvement observed after bariatric surgery including other intestinal gut hormones (GLP-2, PYY), ghrelin (anorexic hormone secreted by the gastric fundus), adipokines, the increased energy expenditure following surgery, changes in the gut microbiome and bile acid (BA) metabolism (49).

BA are increasingly recognized as molecules with endocrine functions, and a link between BA and glycemic control has been suggested. Human studies and animal models support that RYGB promotes a rise in BA concentrations (65). Plasma BA bind to the G-proteincoupled receptor (TGR5) that is present in enteroendocrine cells, liver, skeletal muscle and brown adipose tissue. The activation of TGR5 increases GLP-1 release, which can improve insulin secretion and insulin sensitivity (66). $\mathrm{BA}$ are also involved in the regulation of hepatic glucose metabolism by the nuclear receptor Farnesoid $X$ Receptor (FXR) pathways. The FXR is highly expressed in the liver and intestine, but also in adipose tissue, the pancreas and the adrenal glands. BA can also improve the glucose profile indirectly via FXR-mediated induction of the fibroblast growth factor 19 (FGF19) in the intestine $(67,68,69)$. A recent animal study conducted by Kohli et al. (70) has demonstrated the metabolic effect of diverting bile to the distal gut. The investigators placed a catheter into the common bile duct of obese rats to drain bile to the distal part of the jejunum. The results highlighted the role of BA in glucose homeostasis control. Unfortunately, only a few human studies have addressed the role of BA in diabetes control after bariatric surgery (71). Patti et al. (71) performed a cross-sectional analysis of fasting and postmeal serum BA and metabolic variable composition in three groups of subjects; post-RYGB group $(n=9)$, nonRYGB group matched to preoperative BMI $(n=5)$, and nonRYGB group matched to current BMI $(n=10)$. Total serum BA concentrations were significantly higher in the RYGB 
group compared to the other two groups. Total BA were also inversely correlated with 2 -h post-meal glucose and fasting triglycerides and positively correlated with adiponectin and peak GLP-1 (follow-up study at 24-48 months).

One target of FXR signaling is the gut bacterial flora (72). Recent findings suggest that intestinal bacteria have an impact on host metabolism, obesity and diabetes (73). It has been observed that gastrointestinal rearrangements after RYGB promote substantial changes on the gut microbiota (74). Studies in mice surrounding fecal transplants from RYGB-treated animals have shown substantial weight loss in comparison with mice containing fecal transplants from sham-treated mice, thus suggesting that changes in gut bacteria after RYGB can modulate body weight of the host organism (75).

\section{Cardiovascular risk}

Bariatric surgery has been shown to resolve or improve cardiovascular risk factors such as diabetes, hypertension and dyslipidemia $(38,41,48,76)$. For instance, Sugerman et al. (76) studied 521 hypertensive patients undergoing RYGB and reported hypertension resolution rates at 1 and 5-7 years after surgery of 66 and 69\%, respectively, with superior outcomes in subjects achieving more EWL. Similar effects were reported in Buchwald's meta-analysis, which demonstrated a hypertension resolution rate of $62 \%$ and improvement in $17 \%$ of patients (16). The retrospective cohort study by Adams et al. (77) also showed sustained decreases in blood pressure during a 10-year period after surgery. However, the SOS study investigators suggest that hypertension seems to reappear in the context of weight regain, even with an overall weight reduction (14).

Weight loss surgery promotes substantial decreases in triglycerides levels as well as improvements in cholesterol profiles $(16,78)$. Zlabek et al. (78) showed a $41 \%$ reduction in serum triglycerides 1 year after RYGB, an elevation in HDL cholesterol by $23 \%$ and lowering of LDL cholesterol by $19 \%$, with sustained beneficial effects on cholesterol profiles up to 2 years follow-up. A long-term follow-up study of morbidly obese patients with T2DM $(n=219)$ reported a $40 \%$ decrease in triglyceride levels and 20\% increase in HDL-C levels (79). These improvements were maintained 2-4 years after surgery.

Very little is known about the effect of bariatric surgery on reducing the vascular complications of T2DM. Observational studies have suggested that bariatric surgery may reduce long-term renal impairment associated with diabetes $(41,80)$. A recent study conducted by our institution evaluated diabetic nephropathy changes after bariatric surgery (81). We followed patients over a 5 -year period measuring urinary albumin excretion serially. Preoperatively, $37.8 \%$ of patients had microalbuminuria or macroalbuminuria. After a mean follow-up of 5.5 years, the abnormal albuminuria resolved in $58.3 \%$ of patients after surgery (81). Another non-randomized study of the effects of BPD vs medical treatment on diabetic complications $(n=110)$ studied long-term renal function after both treatments. Fifty patients completed the 10-year study. Renal function was preserved over 10 years in the BPD group and decreased in the medically treated group (glomerular filtration rate $+13.6 \%$ vs $-45.7 \%$ ) (80). Furthermore, the STAMPEDE STUDY showed improvement of albuminuria in both surgical groups. The urinary albumin-to-creatinine ratio (milligrams of albumin to grams of creatinine) decreased from a median of 9-6 in the RYGB group $(P=0.08)$ and from 12 to 7 in the SG group $(P<0.001)$, as compared with the decrease from 6.5 to 5.5 in the medical arm $(P=0.77)(46)$.

Weight loss surgery has also been shown to improve cardiac function and reverse remodeling of the heart up to 3 years postoperatively (82). Surgery can improve all phases of obesity-related cardiomyopathy, and can improve left ventricular systolic function in patients with severe heart failure who are awaiting heart transplantation (83). However, long-term microvascular and macrovascular benefits after bariatric surgery will require large multicenter clinical trials.

\section{Mortality}

The major goal of bariatric surgery is to decrease mortality. A meta-analysis including 44022 participants from eight trials (mean follow-up of 7.5 years) showed reduced risk of global mortality $(\mathrm{OR}=0.55$, CI $0.49-0.63)$ and cardiovascular mortality $(\mathrm{OR}=0.58$, CI $0.46-0.73)$ after bariatric surgery compared with controls (no surgery) (84). Actually, weight loss surgery can reduce mortality by $30 \%$ (85). In the SOS trial, over a period of up to 10 years, mortality was significantly lower in the surgical group (5.0\%) than in the control group (6.3\%), representing a hazard ratio (HR) of 0.76 (95\% CI 0.59-0.99, $P=0.004)$. It should be noted that while the SOS study was not sufficiently powered to establish specific causes of death, the most common were attributable to cardiovascular-related causes (68). A retrospective cohort study by Adams et al. (77) compared longterm mortality in patients who underwent RYGB $(n=7925)$ with obese control patients matched for age, sex and BMI $(n=7925)$. During a mean follow-up of 7 years, all-cause 
mortality rates were $40 \%$ lower in the surgical group compared with controls (HR, 0.60; 95\% CI 0.45-0.67, $P<0.001)$. Another large study conducted in Canada comparing surgical vs non-surgical treatment for morbid obesity showed a reduction of the relative risk of death of $89 \%$ in the surgery group (9). The mortality in the surgical cohort was $0.68 \%$ compared with $6.17 \%$ for controls (relative risk $0.11,95 \%$ CI 0.04-0.27) (9).

\section{Conclusion}

We are currently witnessing the exciting metamorphosis of bariatric surgery into a specialty concerned with metabolic disease and the damaging effects it imparts on obese individuals. Herein, we have presented several key studies that have advanced our understanding of the safety and efficacy of the various contemporary bariatric surgical procedures and the effect they have on obesityrelated comorbid conditions. Bariatric and metabolic surgery has become one of the most studied fields in medicine, with an ever-growing abundance of new studies surfacing every year. As more comparative data emerges, the long-term risks and benefits of the various bariatric procedures will help aid patient and procedural selection for generations of bariatric surgeons to come. Even more intriguing is the current opinion that the indications for metabolic surgery may change in the near future to include broader, more metabolic indications and gradually move away from stricter weight-based criteria, like the National Institute of Health Guidelines. Studies addressing metabolic outcomes after bariatric surgery in type 2 diabetic patients with BMI $<35$ are beginning to surface, and studies like this likely represent future directions in this dynamic specialty.

\section{Declaration of interest}

The authors declare that there is no conflict of interest that could be perceived as prejudicing the impartiality of the review.

\section{Funding}

This review did not receive any specific grant from any funding agency in the public, commercial or not-for-profit sector.

\section{References}

1 World Health Organisation: Obesity and overweight. Fact sheet $\mathrm{N}^{\circ} 311$. Fact sheet N. 8-11, 2013. http://scholar.google.com/scholar?hl=en\& btnG=Search\&q=intitle:Media+centre+Obesity+and+overweight\#5.
2 Allender S \& Rayner M. The burden of overweight and obesity-related ill health in the UK. Obesity Reviews 20078 467-473. (doi:10.1111/j.1467789X.2007.00394.x)

3 Ford ES, Giles WH \& Dietz WH. Prevalence of the metabolic syndrome among US adults: findings from the third National Health and Nutrition Examination Survey. Journal of the American Medical Association 2002287 356-359. (doi:10.1001/jama.287.3.356)

4 Third Report of the National Cholesterol Education Program (NCEP) Expert Panel on Detection, Evaluation, and Treatment of High Blood Cholesterol in Adults (Adult Treatment Panel III) final report. Circulation 2002106 3143-3421.

5 Wang Y, Beydoun MA, Liang L, Caballero B \& Kumanyika SK. Will all Americans become overweight or obese? estimating the progression and cost of the US obesity epidemic Obesity 200816 2323-2330. (doi:10.1038/oby.2008.351)

6 Sjöström CD, Lissner L, Wedel H \& Sjöström L. Reduction in incidence of diabetes, hypertension and lipid disturbances after intentional weight loss induced by bariatric surgery: the SOS Intervention Study. Obesity Research 19997 477-484.

7 Adams TD, Davidson LE, Litwin SE, Kolotkin RL, LaMonte MJ, Pendleton RC, Strong MB, Vinik R, Wanner NA, Hopkins PN et al. Health benefits of gastric bypass surgery after 6 years. Journal of the American Medical Association 2012308 1122-1131. (doi:10.1001/2012. jama.11164)

8 Flum DR, Belle SH, King WC, Wahed AS, Berk P, Chapman W, Pories W, Courcoulas A, McCloskey C, Mitchell J et al. Perioperative safety in the longitudinal assessment of bariatric surgery. New England Journal of Medicine 2009361 445-454. (doi:10.1056/ NEJMoa0901836)

9 Christou NV, Sampalis JS, Liberman M, Look D, Auger S, McLean AP \& MacLean LD. Surgery decreases long-term mortality, morbidity, and health care use in morbidly obese patients. Annals of Surgery 2004240 416-423. (doi:10.1097/01.sla.0000137343.63376.19)

10 Flum DR \& Dellinger EP. Impact of gastric bypass operation on survival: a population-based analysis. Journal of the American College of Surgeons 2004199 543-551. (doi:10.1016/j.jamcollsurg. 2004.06.014)

11 Karlsson J, Taft C, Rydén A, Sjöström L \& Sullivan M. Ten-year trends in health-related quality of life after surgical and conventional treatment for severe obesity: the SOS intervention study. International Journal of Obesity 200731 1248-1261. (doi:10.1038/sj.ijo. 0803573)

12 Dixon JB, Le Roux CW, Rubino F \& Zimmet P. Bariatric surgery for type 2 diabetes. Lancet 2012379 2300-2311. (doi:10.1016/S0140-6736 (12)60401-2)

13 Angrisani L, Santonicola A, Iovino P, Formisano G, Buchwald H \& Scopinaro N. Bariatric Surgery Worldwide 2013. Obesity Surgery 201525 1822-1832. (doi:10.1007/s11695-015-1657-z)

14 Sjöström L, Peltonen M, Jacobson P, Sjöström CD, Karason K, Wedel H, Ahlin S, Anveden $\AA$, Bengtsson C, Bergmark G et al. Bariatric surgery and long-term cardiovascular events. Journal of the American Medical Association 2012307 56-65. (doi:10.1001/jama.2011.1914)

15 Pories WJ, Swanson MS, MacDonald KG, Long SB, Morris PG, Brown BM, Barakat HA, deRamon RA, Israel G \& Dolezal JM. Who would have thought it? An operation proves to be the most effective therapy for adult-onset diabetes mellitus Annals of Surgery 1995222 339-350. (doi:10.1097/00000658-19950900000011)

16 Buchwald H, Avidor Y, Braunwald E, Jensen MD, Pories W, Fahrbach K $\&$ Schoelles K. Bariatric surgery: a systematic review and meta-analysis. Journal of the American Medical Association 2004292 1724-1737. (doi:10.1001/jama.292.14.1724)

17 O'Brien P, McPhail T, Chaston T \& Dixon J. Systematic review of medium-term weight loss after bariatric operations. Obesity Surgery 200616 1032-1040. (doi:10.1381/096089206778026316) 
18 Nelson DW, Blair KS \& Martin MJ. Analysis of obesity-related outcomes and bariatric failure rates with the duodenal switch vs gastric bypass for morbid obesity. Archives of Surgery 2012147 847-854. (doi:10.1001/ archsurg.2012.1654)

19 O'Brien PE, MacDonald L, Anderson M, Brennan L \& Brown WA. Long-term outcomes after bariatric surgery: fifteen-year follow-up of adjustable gastric banding and a systematic review of the bariatric surgical literature. Annals of Surgery 2013257 87-94. (doi:10.1097/SLA. Ob013e31827b6c02)

20 Chakravarty PD, McLaughlin E, Whittaker D, Byrne E, Cowan E, Xu K, Bruce DM \& Ford JA. Comparison of laparoscopic adjustable gastric banding (LAGB) with other bariatric procedures; a systematic review of the randomised controlled trials. Surgeon $201210172-182$. (doi:10.1016/j.surge.2012.02.001)

21 Kehagias I, Karamanakos SN, Argentou M \& Kalfarentzos F. Randomized clinical trial of laparoscopic Roux-en-Y gastric bypass versus laparoscopic sleeve gastrectomy for the management of patients with BMI $<50$ kg/m². Obesity Surgery 201121 1650-1656. (doi:10.1007/ s11695-011-0479-x)

22 Rawlins L, Rawlins MP, Brown CC \& Schumacher DL. Sleeve gastrectomy: 5-year outcomes of a single institution. Surgery for Obesity and Related Diseases 20129 21-25. (doi:10.1016/j.soard.2012.08.014)

23 Baptista V \& Wassef W. Bariatric procedures: an update on techniques, outcomes and complications. Current Opinion in Gastroenterology 2013 29 684-693. (doi:10.1097/MOG.0b013e3283651af2)

24 Buchwald H, Estok R, Fahrbach K, Banel D \& Sledge I. Trends in mortality in bariatric surgery: a systematic review and meta-analysis. Surgery 2007142 621-632. (doi:10.1016/j.surg.2007.07.018)

25 Morino M, Toppino M, Forestieri P, Angrisani L, Allaix ME \& Scopinaro N. Mortality after bariatric surgery: analysis of 13,871 morbidly obese patients from a national registry. Annals of Surgery 2007 246 1002-1007. (doi:10.1097/SLA.0b013e31815c404e)

26 Alhamdani A, Wilson M, Jones T, Taqvi L, Gonsalves P, Boyle M, Mahawar K, Balupuri S \& Small PK. Laparoscopic adjustable gastric banding: a 10-year single-centre experience of 575 cases with weight loss following surgery. Obesity Surgery 201222 1029-1038. (doi:10.1007/s11695-012-0645-9)

27 Thornton CM, Rozen WM, So D, Kaplan ED \& Wilkinson S. Reducing band slippage in laparoscopic adjustable gastric banding: the mesh plication pars flaccida technique. Obesity Surgery 200919 1702-1706. (doi:10.1007/s11695-008-9672-y)

28 Himpens J, Cadière G-B, Bazi M, Vouche M, Cadière B \& Dapri G. Long-term outcomes of laparoscopic adjustable gastric banding. Archives of Surgery 2011146 802-807. (doi:10.1001/archsurg.2011.45)

29 Bauman RW \& Pirrello JR. Internal hernia at Petersen's space after laparoscopic Roux-en-Y gastric bypass: $6.2 \%$ incidence without closure - a single surgeon series of 1047 cases. Surgery for Obesity and Related Diseases 20085 565-570. (doi:10.1016/j.soard.2008.10.013)

30 Gandhi AD, Patel RA \& Brolin RE. Elective laparoscopy for herald symptoms of mesenteric/internal hernia after laparoscopic Roux-en-Y gastric bypass. Surgery for Obesity and Related Diseases 20085 144-149. (doi:10.1016/j.soard.2008.11.002)

31 Yimcharoen P, Heneghan H, Chand B, Talarico JA, Tariq N, Kroh M \& Brethauer SA. Successful management of gastrojejunal strictures after gastric bypass: is timing important? Surgery for Obesity and Related Diseases 20118 151-157. (doi:10.1016/j.soard.2011.01.043)

32 Bolen SD, Chang H-Y, Weiner JP, Richards TM, Shore AD, Goodwin SM, Johns RA, Magnuson TH \& Clark JM. Clinical outcomes after bariatric surgery: a five-year matched cohort analysis in seven US states. Obesity Surgery 201222 749-763. (doi:10.1007/s11695-012-0595-2)

33 El-Hayek K, Timratana P, Shimizu H \& Chand B. Marginal ulcer after Roux-en-Y gastric bypass: what have we really learned? Surgical Endoscopy 201226 2789-2796. (doi:10.1007/s00464-012-2280-x)

34 Love AL \& Billett HH. Obesity, bariatric surgery, and iron deficiency: true, true, true and related. American Journal of Hematology $2008 \mathbf{8 3}$ 403-409. (doi:10.1002/ajh.21106)
35 Shankar P, Boylan M \& Sriram K. Micronutrient deficiencies after bariatric surgery. Nutrition 200926 1031-1037. (doi:10.1016/j.nut. 2009.12.003)

36 Inabnet WB, Winegar DA, Sherif B \& Sarr MG. Early outcomes of bariatric surgery in patients with metabolic syndrome: an analysis of the bariatric outcomes longitudinal database. Journal of the American College of Surgeons 2012214 550-556. (doi:10.1016/j.jamcollsurg.2011. 12.019)

37 Rao RS \& Kini S. Diabetic and bariatric surgery: a review of the recent trends. Surgical Endoscopy 201226 893-903. (doi:10.1007/s00464-0111976-7)

38 Buchwald H, Estok R, Fahrbach K, Banel D, Jensen MD, Pories WJ, Bantle JP \& Sledge I. Weight and type 2 diabetes after bariatric surgery: systematic review and meta-analysis. American Journal of Medicine 2009 122 248-256e5. (doi:10.1016/j.amjmed.2008.09.041)

39 Hayes MT, Hunt LA, Foo J, Tychinskaya Y \& Stubbs RS. A model for predicting the resolution of type 2 diabetes in severely obese subjects following Roux-en Y gastric bypass surgery. Obesity Surgery 201121 910-916. (doi:10.1007/s11695-011-0370-9)

40 Lebovitz HE. Metabolic surgery for type 2 diabetes: appraisal of clinical evidence and review of randomized controlled clinical trials comparing surgery with medical therapy. Current Atherosclerosis Reports 201315 376. (doi:10.1007/s11883-013-0376-y)

41 Brethauer SA, Aminian A, Romero-Talamás H, Batayyah E, Mackey J, Kennedy L, Kashyap SR, Kirwan JP, Rogula T, Kroh M etal. Can diabetes be surgically cured? Long-term metabolic effects of bariatric surgery in obese patients with type 2 diabetes mellitus Annals of Surgery 2013258 628-636.

42 Dixon JB, O’Brien PE, Playfair J, Chapman L, Schachter LM, Skinner S, Proietto J, Bailey M \& Anderson M. Adjustable gastric banding and conventional therapy for type 2 diabetes: a randomized controlled trial. Journal of the American Medical Association 2008299 316-323. (doi:10.1001/jama.299.3.316)

43 Ikramuddin S, Korner J, Lee W-J, Connett JE, Inabnet WB, Billington CJ, Thomas AJ, Leslie DB, Chong K, Jeffery RW et al. Roux-en-Y gastric bypass vs intensive medical management for the control of type 2 diabetes, hypertension, and hyperlipidemia: the Diabetes Surgery Study randomized clinical trial. Journal of the American Medical Association 2013309 2240-2249. (doi:10.1001/jama.2013.5835)

44 Mingrone G, Panunzi S, De Gaetano A, Guidone C, Iaconelli A, Leccesi L, Nanni G, Pomp A, Castagneto M, Ghirlanda G et al. Bariatric surgery versus conventional medical therapy for type 2 diabetes. New England Journal of Medicine 2012366 1577-1585. (doi:10.1056/ NEJMoa1200111)

45 Schauer PR, Kashyap SR, Wolski K, Brethauer SA, Kirwan JP, Pothier CE, Thomas S, Abood B, Nissen SE \& Bhatt DL. Bariatric surgery versus intensive medical therapy in obese patients with diabetes. New England Journal of Medicine 2012366 1567-1576. (doi:10.1056/NEJMoa 1200225)

46 Schauer PR, Bhatt DL, Kirwan JP, Wolski K, Brethauer SA, Navaneethan SD, Aminian A, Pothier CE, Kim ES, Nissen SE et al. Bariatric surgery versus intensive medical therapy for diabetes - 3-year outcomes. New England Journal of Medicine 2014370 2002-2013. (doi:10.1056/NEJMoa1401329)

47 Liang Z, Wu Q, Chen B, Yu P, Zhao H \& Ouyang X. Effect of laparoscopic Roux-en-Y gastric bypass surgery on type 2 diabetes mellitus with hypertension: a randomized controlled trial. Diabetes Research and Clinical Practice 2013101 50-56. (doi:10.1016/j.diabres. 2013.04.005)

48 Schauer PR, Burguera B, Ikramuddin S, Cottam D, Gourash W, Hamad G, Eid GM, Mattar S, Ramanathan R, Barinas-Mitchel E et al. Effect of laparoscopic Roux-en Y gastric bypass on type 2 diabetes mellitus. Annals of Surgery 2003238 467-484. (doi:10.1097/01.sla. 0000089851.41115.1b)

49 Halperin F \& Goldfine AB. Metabolic surgery for type 2 diabetes: efficacy and risks. Current Opinion in Endocrinology, Diabetes, and Obesity 201320 98-105. (doi:10.1097/MED.0b013e32835edbb0) 
50 Rubino F, Forgione A, Cummings DE, Vix M, Gnuli D, Mingrone G, Castagneto M \& Marescaux J. The mechanism of diabetes control after gastrointestinal bypass surgery reveals a role of the proximal small intestine in the pathophysiology of type 2 diabetes. Annals of Surgery 2006244 741-749. (doi:10.1097/01.sla.0000224726. 61448.1b)

51 Schouten R, Rijs CS, Bouvy ND, Hameeteman W, Koek GH, Janssen IM \& Greve JW. A multicenter, randomized efficacy study of the EndoBarrier Gastrointestinal Liner for presurgical weight loss prior to bariatric surgery. Annals of Surgery 2010251 236-243. (doi:10.1097/ SLA.0b013e3181bdfbff)

52 Strader AD, Vahl TP, Jandacek RJ, Woods SC, D’Alessio DA \& Seeley RJ. Weight loss through ileal transposition is accompanied by increased ileal hormone secretion and synthesis in rats. American Journal of Physiology. Endocrinology and Metabolism 2005288 E447-E453. (doi:10.1152/ajpendo.00153.2004)

53 Holst JJ. The physiology of glucagon-like peptide 1. Physiological Reviews 200787 1409-1439. (doi:10.1152/physrev.00034.2006)

54 Jørgensen NB, Jacobsen SH, Dirksen C, Bojsen-Møller KN, Naver L, Hvolris L, Clausen TR, Wulff BS, Worm D, Lindqvist Hansen D et al. Acute and long-term effects of Roux-en-Y gastric bypass on glucose metabolism in subjects with type 2 diabetes and normal glucose tolerance. American Journal of Physiology. Endocrinology and Metabolism 2012303 E122-E131. (doi:10.1152/ajpendo.00073.2012)

55 Jørgensen NB, Dirksen C, Bojsen-Møller KN, Jacobsen SH, Worm D, Hansen DL, Kristiansen VB, Naver L, Madsbad S \& Holst JJ. Exaggerated glucagon-like peptide 1 response is important for improved $\beta$-cell function and glucose tolerance after Roux-en-Y gastric bypass in patients with type 2 diabetes. Diabetes 201362 3044-3052. (doi:10.2337/db13-0022)

56 Chambers AP, Smith EP, Begg DP, Grayson BE, Sisley S, Greer T, Sorrell J, Lemmen L, LaSance K, Woods SC et al. Regulation of gastric emptying rate and its role in nutrient-induced GLP-1 secretion in rats after vertical sleeve gastrectomy. American Journal of Physiology. Endocrinology and Metabolism 2014306 E424-E432. (doi:10.1152/ ajpendo.00469.2013)

57 Jiménez A, Casamitjana R, Viaplana-Masclans J, Lacy A \& Vidal J. GLP-1 action and glucose tolerance in subjects with remission of type 2 diabetes after gastric bypass surgery. Diabetes Care $2013 \mathbf{3 6}$ 2062-2069. (doi:10.2337/dc12-1535)

58 Jiménez A, Mari A, Casamitjana R, Lacy A, Ferrannini E \& Vidal J. GLP-1 and glucose tolerance after sleeve gastrectomy in morbidly obese subjects with type 2 diabetes. Diabetes 201463 3372-3377. (doi:10.2337/db14-0357)

59 Laferrère B, Heshka S, Wang K, Khan Y, McGinty J, Teixeira J, Hart AB \& Olivan B. Incretin levels and effect are markedly enhanced 1 month after Roux-en-Y gastric bypass surgery in obese patients with type 2 diabetes. Diabetes Care 200730 1709-1716. (doi:10.2337/dc06-1549)

60 Vidal J \& Jiménez A. Diabetes remission following metabolic surgery: is GLP-1 the culprit? Current Atherosclerosis Reports 201315357. (doi:10.1007/s11883-013-0357-1)

61 Shah M, Law JH, Micheletto F, Sathananthan M, Dalla Man C, Cobelli C, Rizza RA, Camilleri M, Zinsmeister AR \& Vella A. Contribution of endogenous glucagon-like peptide 1 to glucose metabolism after Roux-en-Y gastric bypass. Diabetes 201463 483-493. (doi:10.2337/db13-0954)

62 Seeley RJ, Chambers AP \& Sandoval DA. The role of gut adaptation in the potent effects of multiple bariatric surgeries on obesity and diabetes. Cell Metabolism 201521 369-378. (doi:10.1016/j.cmet.2015. 01.001)

63 Chambers AP, Stefater MA, Wilson-Perez HE, Jessen L, Sisley S, Ryan KK, Gaitonde S, Sorrell JE, Toure M, Berger J et al. Similar effects of Roux-en-Y gastric bypass and vertical sleeve gastrectomy on glucose regulation in rats. Physiology \& Behavior 2011105 120-123. (doi:10.1016/j.physbeh.2011.05.026)
64 Jiménez A, Casamitjana R, Flores L, Viaplana J, Corcelles R, Lacy A \& Vidal J. Long-term effects of sleeve gastrectomy and Roux-en-Y gastric bypass surgery on type 2 diabetes mellitus in morbidly obese subjects. Annals of Surgery 2012256 1023-1029. (doi:10.1097/SLA. 0b013e318262ee6b)

65 Pournaras DJ, Glicksman C, Vincent RP, Kuganolipava S, AlaghbandZadeh J, Mahon D, Bekker JH, Ghatei MA, Bloom SR, Walters JR et al. The role of bile after Roux-en-Y gastric bypass in promoting weight loss and improving glycaemic control. Endocrinology 2012153 3613-3619. (doi:10.1210/en.2011-2145)

66 Thomas C, Gioiello A, Noriega L, Strehle A, Oury J, Rizzo G, Macchiarulo A, Yamamoto H, Mataki C, Pruzanski M et al. TGR5-mediated bile acid sensing controls glucose homeostasis. Cell Metabolism 200910 167-177. (doi:10.1016/j.cmet.2009.08.001)

67 Prawitt J, Abdelkarim M, Stroeve JH, Popescu I, Duez H, Velagapudi VR, Dumont J, Bouchaert E, van Dijk TH, Lucas A et al. Farnesoid X receptor deficiency improves glucose homeostasis in mouse models of obesity. Diabetes 201160 1861-1871. (doi:10.2337/db11-0030)

68 Prawitt J, Caron S \& Staels B. Bile acid metabolism and the pathogenesis of type 2 diabetes. Current Diabetes Reports 201111 160-166. (doi:10.1007/s11892-011-0187-x)

69 Staels B \& Kuipers F. Bile acid sequestrants and the treatment of type 2 diabetes mellitus. Drugs 200767 1383-1392. (doi:10.2165/ 00003495-200767100-00001)

70 Kohli R, Setchell KD, Kirby M, Myronovych A, Ryan KK, Ibrahim SH, Berger J, Smith K, Toure M, Woods SC et al. A surgical model in male obese rats uncovers protective effects of bile acids post-bariatric surgery. Endocrinology 2013154 2341-2351. (doi:10.1210/en.2012-2069)

71 Patti M-E, Houten SM, Bianco AC, Bernier R, Larsen PR, Holst JJ, Badman MK, Maratos-Flier E, Mun EC, Pihlajamaki J et al. Serum bile acids are higher in humans with prior gastric bypass: potential contribution to improved glucose and lipid metabolism. Obesity 2009 17 1671-1677. (doi:10.1038/oby.2009.102)

72 Sayin SI, Wahlström A, Felin J, Jäntti S, Marschall H-U, Bamberg K, Angelin B, Hyötyläinen T, Orešič M \& Bäckhed F. Gut microbiota regulates bile acid metabolism by reducing the levels of tauro- $\beta$ muricholic acid, a naturally occurring FXR antagonist. Cell Metabolism 201317 225-235. (doi:10.1016/j.cmet.2013.01.003)

73 Sommer F \& Bäckhed F. The gut microbiota - masters of host development and physiology. Nature Reviews. Microbiology 201311 227-238. (doi:10.1038/nrmicro2974)

74 Aron-Wisnewsky J \& Clement K. The effects of gastrointestinal surgery on gut microbiota: potential contribution to improved insulin sensitivity. Current Atherosclerosis Reports 201416 454. (doi:10.1007/ s11883-014-0454-9)

75 Liou AP, Paziuk M, Luevano J-M, Machineni S, Turnbaugh PJ \& Kaplan LM. Conserved shifts in the gut microbiota due to gastric bypass reduce host weight and adiposity. Science Translational Medicine 20135 178. (doi:10.1126/scitranslmed.3005687)

76 Sugerman HJ, Wolfe LG, Sica DA \& Clore JN. Diabetes and hypertension in severe obesity and effects of gastric bypass-induced weight loss. Annals of Surgery 2003237 751-756. (doi:10.1097/01.SLA.0000071560. 76194.11)

77 Adams TD, Gress RE, Smith SC, Halverson RC, Simper SC, Rosamond WD, Lamonte MJ, Stroup AM \& Hunt SC. Long-term mortality after gastric bypass surgery. New England Journal of Medicine 2007357 753-761. (doi:10.1056/NEJMoa066603)

78 Zlabek JA, Grimm MS, Larson CJ, Mathiason MA, Lambert PJ \& Kothari SN. The effect of laparoscopic gastric bypass surgery on dyslipidemia in severely obese patients. Surgery for Obesity and Related Diseases 2005 1537-542. (doi:10.1016/j.soard. 2005.09.009)

79 Kim S \& Richards WO. Long-term follow-up of the metabolic profiles in obese patients with type 2 diabetes mellitus after Roux-en-Y gastric bypass. Annals of Surgery 2010251 1049-1055. (doi:10.1097/SLA. 0b013e3181d9769b) 
80 Iaconelli A, Panunzi S, De Gaetano A, Manco M, Guidone C, Leccesi L, Gniuli D, Nanni G, Castagneto M, Ghirlanda G et al. Effects of bilio-pancreatic diversion on diabetic complications: a 10-year follow-up. Diabetes Care 201134 561-567. (doi:10.2337/ dc10-1761)

81 Heneghan HM, Cetin D, Navaneethan SD, Orzech N, Brethauer SA \& Schauer PR. Effects of bariatric surgery on diabetic nephropathy after 5 years of follow-up. Surgery for Obesity and Related Diseases 20129 7-14. (doi:10.1016/j.soard.2012.08.016)

82 Ashrafian H, Le Roux CW, Darzi A \& Athanasiou T. Effects of bariatric surgery on cardiovascular function. Circulation 2008118 2091-2102. (doi:10.1161/CIRCULATIONAHA.107.721027)
83 Huffman C, Wagman G, Fudim M, Zolty R \& Vittorio T. Reversible cardiomyopathies - a review. Transplantation Proceedings 201042 3673-3678. (doi:10.1016/j.transproceed.2010.08.034)

84 Pontiroli AE \& Morabito A. Long-term prevention of mortality in morbid obesity through bariatric surgery. A systematic review and meta-analysis of trials performed with gastric banding and gastric bypass. Annals of Surgery 2011253 484-487. (doi:10.1097/SLA. 0b013e31820d98cb)

85 Sjöström L, Narbro K, Sjöström CD, Karason K, Larsson B, Wedel H, Lystig T, Sullivan M, Bouchard C, Carlsson B et al. Effects of bariatric surgery on mortality in Swedish obese subjects. New England Journal of Medicine 2007357 741-752. (doi:10.1056/NEJMoa066254)

Received 5 June 2015

Revised version received 15 August 2015

Accepted 3 September 2015 